\section{Evaluation of Biological Agents for Control of Macrophomina Root Rot and Powdery Mildew in Flowering Dogwood (Cornus florida L.)}

\author{
Margaret T. Mmbaga ${ }^{1}$ and Lucas M. Mackasmiel \\ Department of Agricultural and Environmental Sciences, College of \\ Agriculture, Tennessee State University, Nashville, TN 37209
}

Frank A. Mrema

Research and Applied Sciences, Alcorn State University, Lorman, MS 39096

Additional index words. fungicides, Macrophomina phaseolina, Erysiphe pulchra, Stenotrophomonas, Serratia, soil-borne pathogens

\begin{abstract}
Six biological control agents (BCAs) (two bacteria, two fungi, and two yeasts) that were previously shown to be effective against powdery mildew (Erysiphe pulchra) were tested for efficacy against Macrophomina phaseolina root rot on flowering dogwood (Cornus florida) in the greenhouse. Two of the bacterial isolates, Stenotrophomonas sp. (B17A) and Serratia sp. (B17B), were effective in controlling both macrophomina root rot and powdery mildew, similar to fungicide control thiophanate methyl, when roots were drenched with the six BCAs individually. In addition, the two bacterial BCAs improved plant growth with respect to stem diameter, stem length, dry weight, and green foliage compared with fungicide-treated plants or nontreated controls grown in sterile soil. These results confirm previous results in which $B 17 \mathrm{~A}$ and $\mathrm{B} 17 \mathrm{~B}$ suppressed powdery mildew and also promoted plant growth in flowering dogwood. Although macrophomina root rot has been previously reported as a potential problem in flowering dogwood, especially in field conditions, simultaneous infection with macrophomina root rot and powdery mildew has not been previously reported. This study confirmed that $M$. phaseolina infection was characterized by stubby roots and black root lesions, and plants infected with both powdery mildew and macrophomina root rot had smaller root mass compared with fungicide-treated plants. Neither of the two pathogens killed their host plants, but compounded infections significantly reduced the plant root system and plant growth. The efficacy of the two bacterial isolates in controlling both powdery mildew and macrophomina root rot suggests their potential utilization in controlling both diseases in dogwood nursery production and in other plants that are hosts to both powdery mildew and macrophomina root rot. Plant growth promoted by the two BCAs may be attributed to powdery mildew and macrophomina root rot control, but comparisons between fungicide-treated plants and control plants not inoculated with BCAs or root rot pathogen suggested that the two BCAs may play a role as bio-stimulants in growth enhancement. These results also suggest that the two biocontrol agents are not phytotoxic to dogwood.
\end{abstract}

Macrophomina phaseolina is a nonspecialized soil-borne pathogen that can become a problem by causing root rot, charcoal rot, collar rot, damping-off, wilt, leaf blight, and stem blight in both agricultural and natural or landscape environments. More than 500 plant species are affected across $\approx 100$ families, including the dogwood family (Farr et al., 1989; Smith and Carvil, 1977). Woody ornamental plants affected by this fungus include pine, douglas fir, and the highly valued

Received for publication 14 Mar. 2018. Accepted for publication 9 May 2018.

We would like to thank Richard Hall for his critical review of this manuscript. The research was partly funded by USDA-NIFA capacity building grants, project no. TENX-2010-02399.

${ }^{1}$ Corresponding author. E-mail: mmmbaga@tnstate. edu.

HortScience Vol. 53(10) October 2018 the impact of compounded infections on plant growth has not been evaluated. Such information would have significant implications on disease management in nursery production systems that have been already devastated by powdery mildew since the disease emerged in early 1990s (Mmbaga, 2000; Windham, 1994).

The main symptoms of powdery mildew are a powdery appearance on plant foliage, stunted plant growth, defoliation, and plant health decline (Chartfield and Rose, 1996; Mmbaga et al., 2007). Leaf scorching and leaf reddening has also been associated with dogwood powdery mildew (Mmbaga, 2000; Mmbaga and Sauvé, 2004a; Mmbaga et al., 2004; Windham, 1994). Studies on powdery mildew in oak (Quercus robur) leaves reported increases in plant respiration and transpiration and reduced leaf lifespan that may lead to decreased carbon uptake over the growth season (Hajji et al., 2009). A similar phenomenon may occur in dogwoods infected with powdery mildew. Recent studies have shown that M. phaseolina causes stubby roots and reduces root mass in seedlings of flowering dogwoods (Mmbaga et al., 2018). This study was conducted to evaluate the impact of compounded infection from $M$. phaseolina and E. pulchra on dogwood plant growth; such information would provide a better understanding of factors that may contribute to dogwood decline.

Fungicides are routinely used to control powdery mildew in nursery production of flowering dogwood (Hagan et al., 2005; Li et al., 2009; Mmbaga and Sauvé, 2004b; Windham, 1994), but that practice has caused concerns over environmental and health hazards to human applicators and nontarget organisms including beneficial microflora. Previous studies have shown that native plants in natural environments, where fungicides have never been used, harbor microorganisms that suppress powdery mildew in flowering dogwood (Mmbaga and Sauvé, 2009; Mmbaga et al., 2007, 2016). Out of the microorganisms isolated from native plants in natural environments, Stenotrophomonas sp. (B17A) and Serratia sp. (B17B) were highly effective in controlling powdery mildew in seedling populations by disrupting spore germination (Mmbaga et al., 2016). In addition, the applications of the two bacteria by root drenching suppressed powdery mildew similarly to foliage sprays and suggested that the BCAs may also cause induced systemic resistance (ISR), which may suppress other fungal pathogens including root rot pathogens (Mmbaga et al., 2016). The objectives of this study were to 1) evaluate the efficiency of six previously selected microbial isolates (B17A, B17B, F13, F16, $\mathrm{Y} 4$, and Y14) as biological control agents for macrophomina root rot and powdery mildew in C. florida; and 2) determine the effect of the BCAs on plant health and plant growth.

\section{Materials and Methods}

Plant material, M. phaseolina inoculum preparation, and plant inoculation. Dogwood 
seeds for this study were collected from fieldgrown $C$. florida at Otis Floyd Nursery Research Center experimental farm (Tennessee State University) in McMinnville, TN and vernalized at $4{ }^{\circ} \mathrm{C}$ to break dormancy. $M$. phaseolina inoculum, previously isolated from dogwood (Mmbaga et al., 2018), was prepared from 5 d-old cultures grown on potato dextrose agar (PDA). Mycelia was scraped from the PDA into sterilized water and macerated using a sterilized hand-held blender. Mycelial fragments were counted using a haemocytometer and used as propagules adjusted to a concentration of $5 \times 10^{4}$ propagules $/ \mathrm{mL}$. The inoculum suspension was applied to heat-sterilized media consisting of Morton's Grow Mix \#2 (Morton's Horticultural Supplies Inc., McMinnville, TN). Thirty $\mathrm{mL}$ of the inoculum suspension was applied in $10.2 \mathrm{~cm}$ plastic pots filled with heat-sterilized media, mixed thoroughly, and allowed to colonize the media for seven days before planting. Dogwood seedlings were then planted in the $M$. phaseolina-infested media and control plants were planted in heatsterilized media. All plants were maintained in a greenhouse at $28 \pm 3{ }^{\circ} \mathrm{C}$, and watered daily by drip irrigation.

$B C A$ inoculum preparation and plant treatment with the BCAs and fungicide. Experimental treatments consisted of six BCAs including two bacteria, Stenotrophomonas sp. (B17A) and Serratia sp. (B17B), previously selected for dogwood powdery mildew control (Mmbaga et al., 2016), two fungi, Acremonium alternatum (F16) and Penicillium spp. (F13), and two yeasts, unidentified species (Y4) and Rhodosporidium sp. (Y14), previously selected as potential BCAs for dogwood powdery mildew (Mmbaga et al., 2007). Bacterial BCA inocula were prepared from $24 \mathrm{~h}$-old cultures grown on nutrient broth (NB) containing $1.0 \mathrm{~g}$ meat extract; $1.0 \mathrm{~g}$ yeast extract; $5.0 \mathrm{~g}$ peptone; and $5.0 \mathrm{~g}$ sodium chloride per L. After $24 \mathrm{~h}$ growth in NB, cells were pelleted by centrifugation, washed twice in sterile water, and then re-suspended in sterile water containing $0.05 \%$ Tween 20 . The BCAs were then grown in nutrient agar and inocula of $3 \times 10^{6}$ colony forming units (cfu) per $\mathrm{mL}$ was prepared from 24 to $48 \mathrm{~h}$ cultures. Yeast inocula were prepared from 7 d-old cultures grown on potato dextrose agar (PDA) and a concentration of $3 \times 10^{6} \mathrm{cfu}$ per $\mathrm{mL}$ was used. Fungal BCA inocula was prepared from 7 d-old cultures grown on PDA and adjusted to $4 \times 10^{6}$ spores $/ \mathrm{mL}$, counted using a haemocytometer. Inocula concentrations of bacteria and yeast BCAs were estimated using optical density readings using a graph curve, previously developed to correspond with specified cfu of each BCA.

The application of BCAs was by drenching to treat the roots using $20 \mathrm{~mL}$ of $\mathrm{BCA}$ inoculum suspension applied to each $10.2 \mathrm{~cm}$ planting container starting in early June/late May, when powdery mildew symptoms were first observed. Efficacy of the six BCAs was compared with the fungicide thiophanatemethyl (Cleary's 3336TM F; Cleary Chemical Corp., Dayton, NJ) and two controls, one consisting of $M$. phaseolina with no BCAs and another control in sterile soil with no BCA and no M. phaseolina. Powdery mildew inoculum was from natural airborne spores from previously infected plants placed randomly in the greenhouse. Application of BCAs was repeated at 7 to $10 \mathrm{~d}$ intervals through early September/late August to coincide with powdery mildew treatments. The fungicide was prepared at a concentration of $1 \mathrm{~mL}$ per $727.3 \mathrm{~mL}(\mathrm{v} / \mathrm{v})$ water, equivalent to $18 \mathrm{fl} \mathrm{oz} / 100$ gallons according to the manufacturer's recommendations (Cleary's Chemicals Corporation, Dayton, NJ). Fungicide application was by root drenching in which media was soaked through root zone using $20 \mathrm{~mL}$ per container every $14 \mathrm{~d}$. Each treatment was replicated and comprised four containers with three plants per container.
Treatments were arranged in a randomized complete block design.

Assessment of diseases. Powdery mildew severity was evaluated monthly on a scale of 0 to 5 in which $0=$ no infection; $1=1 \%$ to $10 \% ; 2=11 \%$ to $25 \% ; 3=26 \%$ to $50 \% ; 4=$ $51 \%$ to $75 \%$; and $5=76 \%$ to $100 \%$ of the plant foliage covered with powdery mildew symptoms starting one month after planting. The experiment was ended $90 \mathrm{~d}$ after plant inoculation, roots were gently cleaned to remove soil particles, and macrophomina root rot disease severity was evaluated based on root discolorations and deformities, such as root stubbiness and presence or absence of small feeder roots, and visual root mass. Root rot incidence was estimated on a scale of 0 to 5 in which $0=$ no infection; $1=1 \%$ to $10 \%$; $2=11 \%$ to $25 \% ; 3=26 \%$ to $50 \% ; 4=51 \%$ to $75 \%$; and $5=76 \%$ to $100 \%$ of roots displaying root lesions. Re-isolation of $M$. phaseolina was done on PDA to confirm the presence of M. phaseolina in the root lesions. Some root samples were cleared using $1 \% \mathrm{KOH}$ for $24 \mathrm{~h}$ and stained with $0.05 \%$ aniline blue for observation of microsclerotia under a compound microscope.

Effect of the biocontrol isolates on plant growth. Plant growth was evaluated based on stem length, stem diameter at $\approx 6 \mathrm{~cm}$ above soil level, visual root mass, and oven dry weight based on drying to constant weight. Data were analyzed using SAS 9.1 (SAS Institute, Inc., Cary, NC) general linear models procedure and Fisher's least significant difference test at $P<0.05$.

\section{Results and Discussion}

Plant infection with M. phaseolina and E. pulchra. Dogwood seedlings infected with M. phaseolina and E. pulchra exhibited significant visual differences in plant color and plant size (Fig. 1). Plants treated with bacterial agents B17A and B17B grew consistently
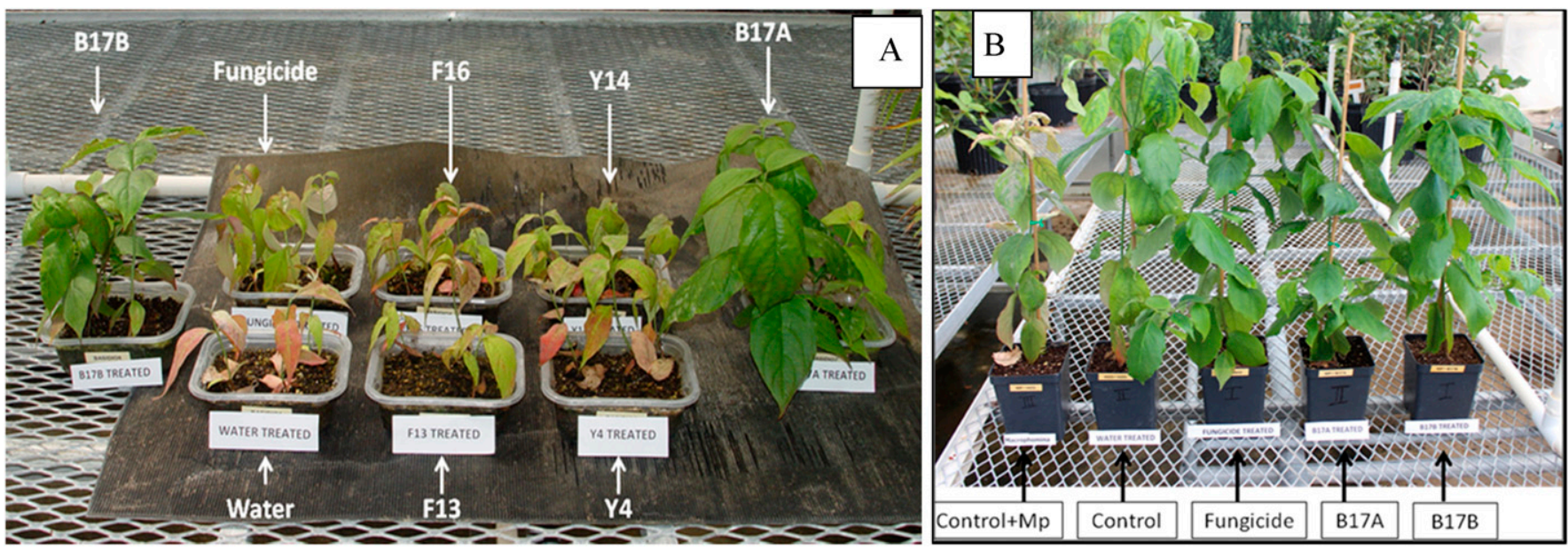

Fig. 1. (A) Effect of six biocontrol agents (BCA) (B17A, B17B, F13, F16, Y4, and Y14), compared with the fungicide thiophanate methyl (fungicide) and nontreated control (water) on dogwood (Cornus florida) seedlings planted in heat sterilized soil infested with Macrophomina phaseolina and then exposed to airborne spores of Erysiphe pulchra, with treatment applied by soil drenching. (B) Overall plant growth and powdery mildew severity in plants treated with bacterial BCA (B17A and B17B) and fungicide (fungicide) compared with control plants with macrophomina root rot and no BCA (Control+Mp) and control plants grown in sterile soil with no BCAs and no macrophomina root rot (Control). 
larger and greener than those treated with thiophanate methyl, or with fungal agents (F13 and F16) or yeast agents (Y4 and Y14). Control plants grown in macrophominainfested media with no BCA (Control $+\mathrm{Mp}$ ) had greater powdery mildew severity than control plants grown with no Macrophomina and no BCA (Figs. 1B and 2). Although the differences were significant in only Expt. 1, they suggest that plants infected with macrophomina root rot are likely to have higher powdery mildew severity. Some reddish coloration of leaves was observed on all treatments except plants treated with B17A and

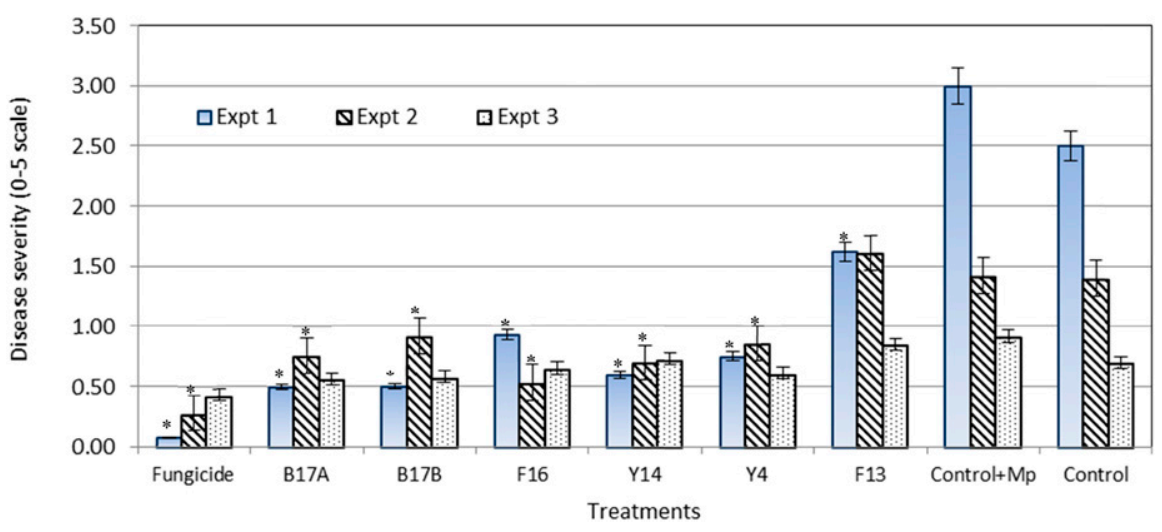

Fig. 2. Powdery mildew disease severity on Cornus florida plants grown in soil infested with Macrophomina phaseolina (Mp) and drenched with six biocontrol agents (B17A, B17B, F16, Y14, Y4, and F13), thiophanate methyl, and nontreated control (Control+Mp) and nontreated control with no macrophomina and no biocontrol (control). Disease severity on a 0 to 5 scale in which $0=$ no infection; $1=1 \%$ to $10 \% ; 2=11 \%$ to $25 \% ; 3=26 \%$ to $50 \% ; 4=51 \%$ to $75 \%$; and $5=76 \%$ to $100 \%$ of plant covered with powdery mildew symptoms. *Significantly different from nontreated control (Control) and Control+Mp at $P<0.05$ in each experiment. Standard error bars at $P<0.05$
B17B (Fig. 1A). The reddish color on leaves obscured the evaluation of powdery appearance associated with powdery mildew disease. However, reddish coloration of leaves has been previously associated with powdery mildew symptoms (Windham, 1994), and it was assumed that the more intense reddish color on leaves was associated with higher incidence of powdery mildew (Fig. 1A). Plants inoculated with M. phaseolina as nontreated controls with no BCA and plants treated with yeast and fungal BCAs (Y14, Y4, F13, and F16) displayed root discolorations and black lesions, and stubby roots with few feeder roots (Fig. 3A-C). These observations suggested that the yeast and fungal BCAs were not effective in reducing root rot (data not shown). Microscopic observations revealed many microsclerotia resting structures in inoculated and not in noninoculated plants. M. phaseolina was re-isolated from root lesions and thus confirmed the presence of $M$. phaseolina as a causal agent for the root rot.

Effect of the biocontrol agents on disease severity. Plants grown in macrophominainfested media without any disease control developed the highest powdery mildew severity and exhibited early defoliation compared with those treated with effective BCAs or fungicide (Fig. 1). Differences in powdery mildew severity between BCA treatments
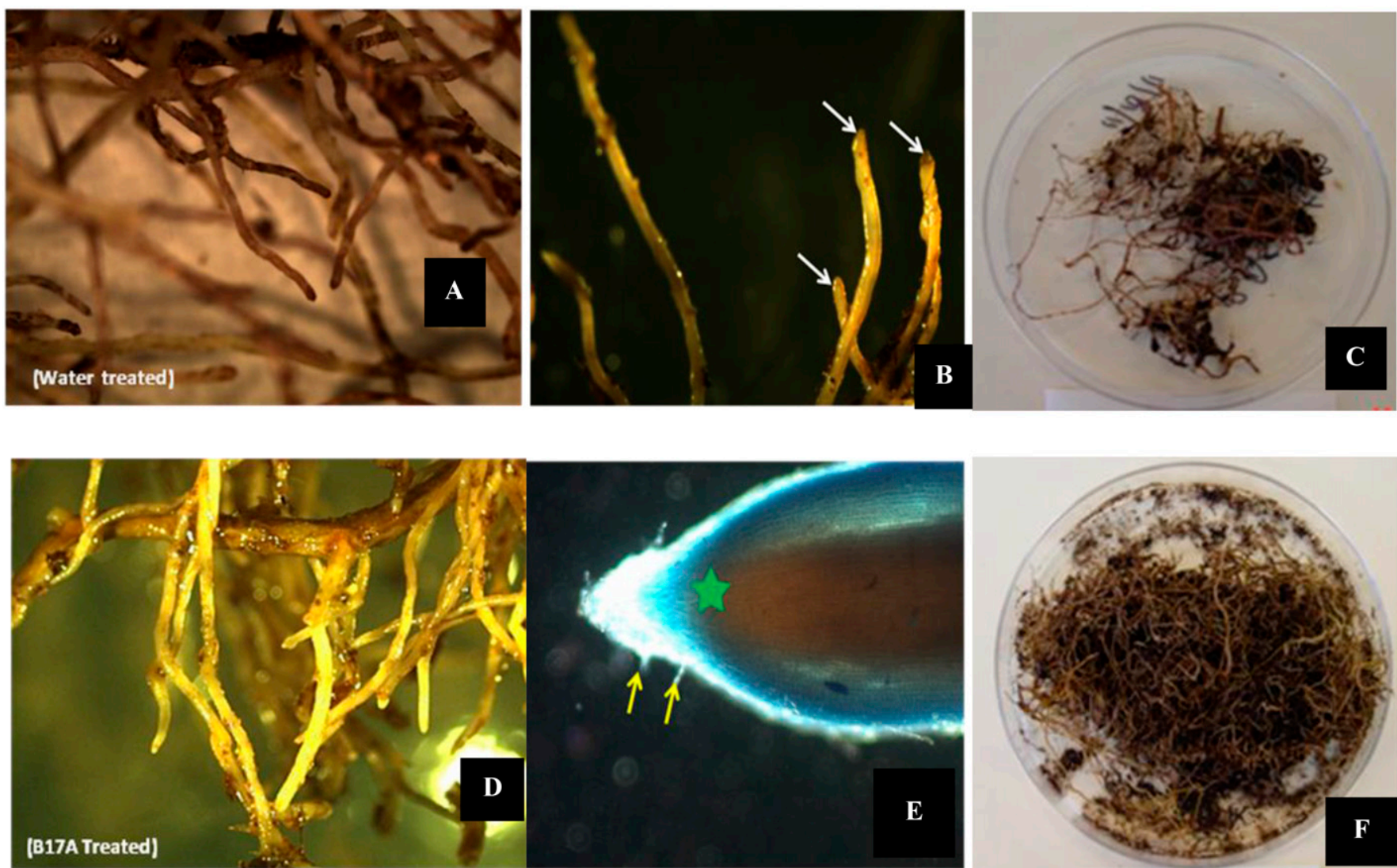

Fig. 3. Roots of flowering dogwood seedlings grown in soil infested with Macrophomina phaseolina and drenched with selected biocontrol agents and the fungicide thiophanate methyl in the greenhouse: (A) root discolorations and (B and $\mathbf{C})$ stubby roots with no feeder roots compared with (D) healthy roots with plenty of feeder roots in effective treatments (B17A, B17B, Fungicide, and control with no macrophomina), (E) root hairs (arrows), and (F) larger root mass in plants treated with effective biocontrol agents B17A, B17B, and fungicide. 
were significant at $P=0.01$ in Expts. 1 and 2 but not significant in Expt. 3 (Fig. 2). Treatments with fungicide had the lowest powdery mildew disease incidence in all three experiments. Treatments with bacterial BCAs (B17A and B17B) and treatment with fungal and yeast BCAs (F16, Y14, and Y4) were also highly effective in suppressing powdery mildew in Expts. 1 and 2, but fungal isolate F13 was not effective (Fig. 2). In Expt. 1, control treatments with M. phaseolina and no BCA treatments had the highest powdery mildew severity followed by the control with no M. phaseolina and no BCA treatment, while in Expt. 2, the two control treatments and fungal BCA F13 had the highest powdery mildew compared with other treatments, the differences being significant at $P=0.05$ (Fig. 2). Overall, powdery mildew severity was very low in Expt. 3 and there were no significant differences in powdery mildew severity between treatments (Fig. 2). Variations in powdery mildew severity in different years are not uncommon because any variations in the amount of airborne inoculum or temperature and moisture impact disease severity (Mmbaga, 2000, 2002).

Results from this study confirmed previous results showing that $\mathrm{B} 17 \mathrm{~A}$ and $\mathrm{B} 17 \mathrm{~B}$ were effective biocontrol agents that may be used to reduce the use of conventional fungicide treatment (Mmbaga et al., 2016). Additional biocontrol agents Y14, Y4, and F16 were confirmed as effective against powdery mildew, and may also be used to reduce conventional fungicide use in powdery mildew control (Fig. 2). However, Y14, Y4, and F16 were not effective in controlling macrophomina root rot (as explained above). Plants treated with bacterial isolates B17A, B17B, or fungicide exhibited healthy roots with plenty of small feeder roots similar to control plants grown in sterile soil with no $M$. phaseolina (Fig. 3D-F); microscopic observation of roots from B17A, B17B, and fungicide treatments revealed abundant root hairs (Fig. 3E). These results showed that B17A and B17B were effective in controlling both powdery mildew and macrophomina root rot.

A number of biocontrol agents have been tested for the control of M. phaseolina in food and cash crops in many parts of the world, and Trichoderma viride, T. harzianum, Pseudomonas fluorescens, and Bacillus subtilis have been shown to inhibit $M$. phaseolina in culture and in the greenhouse environment (Kumar, 2013). The efficacy of the two bacterial isolates in our study in controlling both powdery mildew and macrophomina root rot suggests their potential utilization in dogwood nursery production and in other plants that are hosts to both powdery mildew and macrophomina root rot.

Effect of the biocontrol isolates on plant growth. Significant differences in plant growth were observed between treatments, as shown for stem length, stem diameter as well as oven dry weight $(P<0.01$; Figs. 1,4 , and 5). Plants treated with bacterial BCAs grew significantly larger than fungicide-treated plants and their leaves maintained their green color for longer
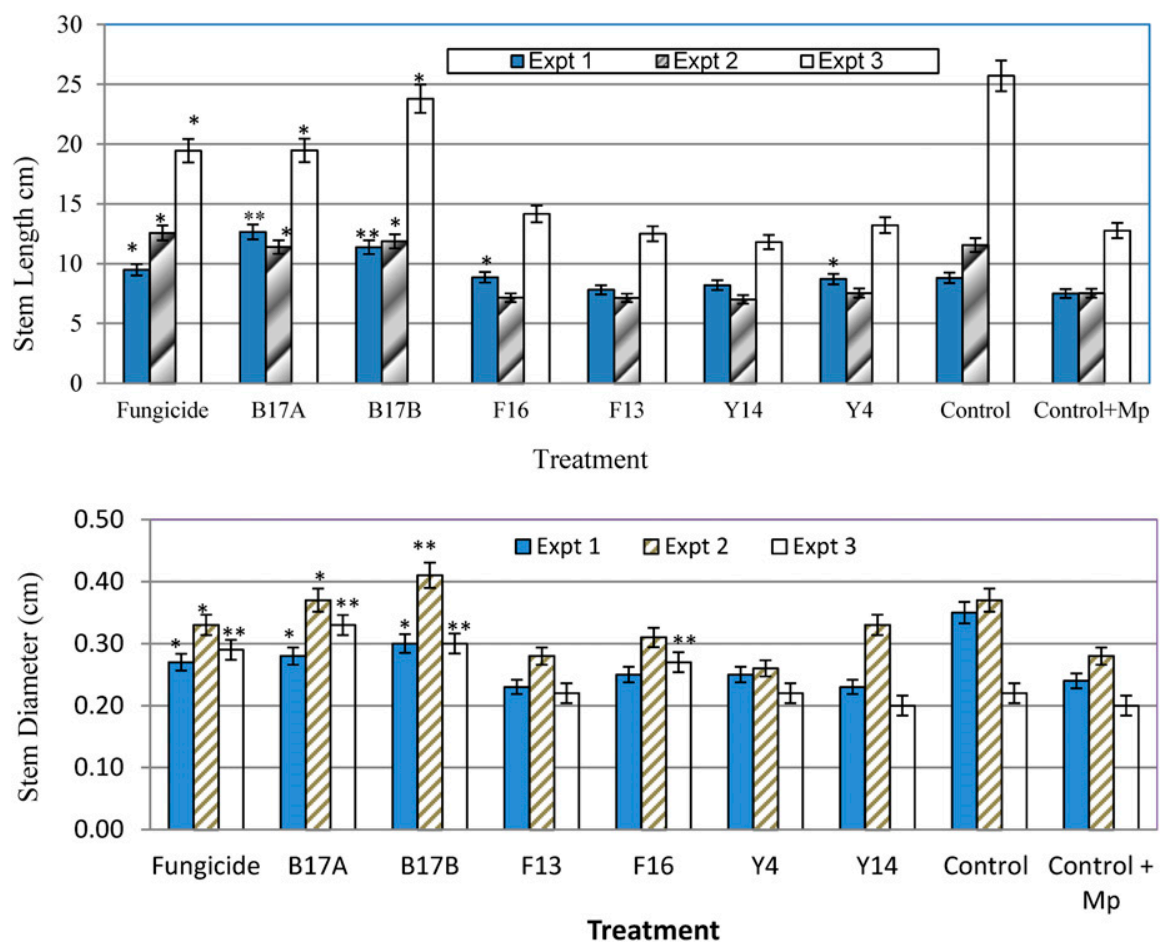

Fig. 4. Stem height and stem diameter as a measure of plant growth in Cornus florida seedlings grown in soil infested with Macrophomina phaseolina and drenched with biocontrol agents (B17A, B17B, F13, F16, Y4, and Y14) and fungicide thiophanate methyl (Fungicide), compared with nontreated control with macrophomina (Control+Mp) and plants grown in sterile soil with no M. phaseolina (Control) *Significantly different from nontreated control with macrophomina (Control+Mp). ${ }^{* * \text { Significantly }}$ different from Control and Control $+\mathrm{Mp}$ at $P<0.05$ in each experiment. Standard error bars at $P<0.05$

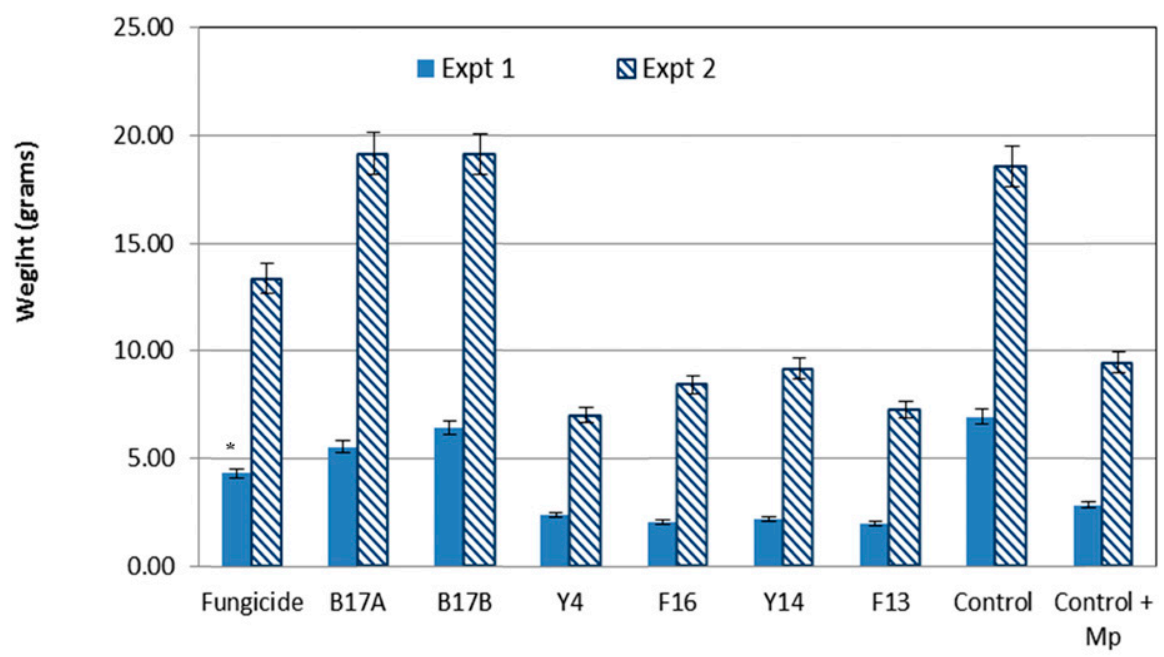

Treatment

Fig. 5. Oven dry weight of Cornus florida seedlings grown in soil infested with Macrophomina phaseolina and treated with biocontrol agents (B17A, B17B, F13, F16, Y4, and Y14) and compared with the fungicide thiophanate methyl (Fungicide), nontreated control (Control+Mp), and plants grown in sterile soil with no macrophomina (Control). No data were taken in Expt 1 . Standard error bars at $P<0.05$.

periods up to the end of the growing season compared with all other treatments with $M$. phaseolina. Plants treated with the two bacterial BCA agents, B17A and B17B, developed more branching, larger leaves and tall stems, even in the presence of M. phaseolina, compared with fungicide-treated plants and other BCA treatments (Figs. 1, 4, and 5). Although the fungicide was slightly more effective than the BCAs (B17A and B17B) in powdery mildew control (Fig. 2), the BCAs promoted stem diameter and oven dry weight better than the fungicide treatment and the macrophomina infected control with no BCA (Fig. 4). Plants exhibited larger stem height and dry weight in Expt. 3 compared with Expts. 1 and 2 (Figs. 4 
and 5). The difference may be explained by unintentional use of slightly larger plants in Expt. 3 compared with Expts. 1 and 2. However, no big differences were observed on stem diameters.

The greatest stem height in Expts. 1 and 2 was with treatments with B17A and B17B followed by fungicide, while in experiment 3 control treatment with no $M$. phaseolina or $\mathrm{BCA}$ and $\mathrm{B} 17 \mathrm{~B}$ had the greatest stem height followed by B17A and fungicide (Fig. 4). Similarly, control treatment in which plants were grown in sterilized media with no $M$. phaseolina or BCA had the greatest stem diameter in Expt. 1 followed by B17B and B17A and fungicide suggesting, that macrophomina root rot had an effect on plant growth and that B17B and B17A positively impacted plant growth by controlling macrophomina root rot (Fig. 4). The greatest stem diameter was in treatment with B17B and B17A in Expt. 2 and B17A in Expt. 3, thereby reinforcing the impact of these bacterial BCAs on disease control and subsequently on plant growth. Similarly, the oven dry weight of plants treated with B17A, B17B, and control treatment with no $M$. phaseolina or BCA was significantly higher than all other BCAs and the fungicide treatment (Fig. 5). These results suggested that macrophomina root rot impacted plant growth as well as powdery mildew severity in repeated experiments (Fig. 1B). The improved plant growth from bacterial BCAs may be attributed to a combination of their ability to control both root rot and powdery mildew severity. However, fungicide applications also controlled both powdery mildew and macrophomina root rot, but fungicide treated plants were smaller and less green than those treated with the bacterial BCAs. Hence, it is likely that the bacterial BCAs had another effect on the plants that may include improved nutrient uptake, or the production of growth hormones and/or other secondary metabolites that impacted plant growth.

Previous studies on bacterial BCAs (B17A and B17B) have demonstrated endophytic colonization of treated dogwood plants and their effects in suppressing powdery mildew severities (Mmbaga et al., 2016). Other studies on the interactions between endophytic bacteria and their host plants were directly linked with beneficial effects such as plant growth promotion and biocontrol activity against plant pathogens (Bashan et al., 1990; Hallmann et al., 1997; Pleban et al., 1995). Waller et al. (2005) reported that root colonization of barley by the endophytic fungus Piriformospora indica reduced the incidence of powdery mildew by inducing systemic resistance in the host plant. The beneficial effect on plant defense was detected in distal leaves, demonstrating a systemic induction of resistance by a root-endophytic fungus (Waller et al., 2005). In addition, Hardoim et al. (2008) reported that some endophytic bacteria promoted host plant growth by producing plant growth-promoting substances and fixing nitrogen $(\mathrm{N})$ from the atmosphere (Sturz et al., 2000).
Although there were slight variations in best disease suppression in different experiments, overall, this study has shown that the presence of $M$. phaseolina in the soil can impact both powdery mildew severity and plant growth (Figs. 1, 4, and 5). BCAs B17A and B17B appear to act as biostimulants and, as such, have the potential to contribute to the minimization of root rot and powdery mildew. The two bacterial BCAs were initially isolated from flowering dogwood in the wild (Mmbaga et al., 2016), suggesting that in natural environments, beneficial microbial disease antagonists may benefit plant growth in different ways. While the results from this study have confirmed previous studies (Mmbaga et al., 2016) on the efficacy of bacterial BCAs B17A and B17B in suppressing powdery mildew in the greenhouse, this study has also demonstrated antagonisms against $M$. phaseolina in compounded infections. The significant effect of B17A and $\mathrm{B} 17 \mathrm{~B}$ in reducing the severity of both diseases and improving plant growth better than a conventional fungicide commonly used in dogwood nursery production suggests a need for more studies on their role as growth promoters as well as their mechanisms of action and efficacy on other root rot pathogens. Reports on an endophytic isolate of Pseudomonas sp. showed its capability in concurrent production of indole acetic acid and solubilization of inorganic phosphate (Bano and Musarrat, 2003; Oteino et al., 2015). The isolate was also associated with significant production of hydrogen cyanide and siderophores that are well documented for their role in biocontrol of soil borne pathogens (Leong, 1986). There is a need to better understand the role of the two BCAs in production of growth-promoting substances and/or their role in nutrient uptake or induced systemic resistance, as well as for analysis of secondary metabolites associated with these BCAs. In addition, field studies are also needed.

\section{Conclusion}

In this study, bacterial isolates B17A and $\mathrm{B} 17 \mathrm{~B}$, yeast isolates $\mathrm{Y} 14$ and $\mathrm{Y} 4$, and fungal isolate F16 suppressed powdery mildew severity, an important disease problem in nursery production of dogwood. B17A and B17B demonstrated superior biocontrol activity by also reducing root rot from $M$. phaseolina. However, isolates Y14, Y4, and F16 were ineffective against macrophomina root rot and isolate F13 was ineffective on both powdery mildew and macrophomina root rot.

\section{Literature Cited}

Bano, N. and J. Musarrat. 2003. Isolation and characterization of phorate degrading bacteria of agricultural significance. Lett. Appl. Microbiol. 36:1-5.

Barnard, E.L. and S.P. Gilly. 1986. Charcoal root rot of pines. Plant Pathology Circ. No. 290. Florida Dept. Agr. and Consumer Serv.

Bashan, Y., S.K. Harrison, and R.E. Whitmoyer. 1990. Enhanced growth of wheat and soybean plants inoculated with Azospirillum brasilense is not necessarily due to general enhancement of mineral uptake. Appl. Environ. Microbiol. 56:769-775.

Chartfield, J.A. and M. A. Rose. 1996. Ornamental Plants Annual Report and Research Summaries. Ohio State University Special Circ. No. 152.

Farr, D.F., G.F. Bills, G.P. Chamuris, and A.Y. Rossman. 1989. Fungi on Plants and Plant Products in the United States. APS Press, St. Paul, MN.

Hagan, A.K., J.W. Olive, J. Stephenson, and M.E. Rivas-Davila. 2005. Comparison of fungicides for the control of powdery mildew on dogwood. Alabama Agricultural Station. Bul. 659.

Hajji, M., E. Dreyer, and B. Marçais. 2009. Impact of Erysiphe alphitoides on transpiration and photosynthesis in Quercus robur leaves. Eur. J. Plant Pathol. 125(1):63.

Hallmann, J., A. Quadt-Hallmann, W.F. Mahaffee, and J.W. Kloepper. 1997. Bacterial endophytes in agricultural crops. Can. J. Microbiol. 43: 895-914.

Hardoim, P.R., L.S. van Overbeek, and J.D. Elsas. 2008. Properties of bacterial endophytes and their proposed role in plant growth. Trends Microbiol. 16:463-471.

Hodges, C.S. 1962. Black root rot of pine seedlings. Phytopathology 52:210-219.

Leong, J. 1986. Sidephore: Their biochemistry and possible role in biocontrol of plant pathogens. Ann. Rev. Plant Pathol. 24:187-209.

Li, Y., M. Mmbaga, A. Windham, M. Windham, and R. Trigiano. 2009. Powdery mildew of dogwoods: Current status and future prospects. Plant Dis. 93:1084-1092.

Lotfalinezhad, E., Z. Mehri, and S.J. Sanei. 2013. Temperature response of Macrophomina phaseolina isolates from different climatic in Iran. Annu. Rev. and Res in Biol. 3:724-734.

Khan, S.N. 2007. Macrophomina phaseolina as causal agent for charcoal rot of sunflower. Mycopath 5:111-118.

Kumar, S. 2013. Trichoderma: A biological control weapon for managing plant diseases and promoting sustainability. Intern J. of Agr. Sci. and Vet Med. 1(3):106-121.

Mmbaga, M.T. 2000. Winter survival and source of primary inoculum for powdery mildew of dogwood in Tennessee. Plant Dis. 84:574-579.

Mmbaga, M.T. 2002. Ascocarp formation and survival and primary inoculum production in Eysiphe (Sect. Microsphaera) pulchra in dogwood powdery mildew. Ann. Appl. Biol. 141: 153-161.

Mmbaga, M.T. and R.J. Sauvé. 2004a. Evaluation for multiple disease resistance in dogwood for three foliar pathogens. Arboric. Urban For. 30(2): 101-106.

Mmbaga, M.T. and R.J. Sauvé. 2004b. Management of powdery mildew in flowering dogwood in the field with biorational and synthetic fungicides. Can. J. Plant Sci. 84:837-844.

Mmbaga, M.T., N. Klopfenstein, M. Kim, A. Shi, and N.C. Mmbaga. 2004. PCR-based DNA analysis of powdery mildew pathogens of dogwood (Cornus spp.). For. Pathol. 34:321-328.

Mmbaga, M.T., R.J. Sauvé, and F.A. Mrema. 2007. Identification of microorganisms for biological control of powdery mildew in Cornus florida. Biol. Control 44:67-72.

Mmbaga, M.T. and R.J. Sauvé. 2009. Epiphytic microbial communities on foliage of fungicidetreated and non-treated flowering dogwoods. Biol. Control 49(2):97-104.

Mmbaga, M.T., F.A. Mrema, L. Mackasmiel, and E. Rotich. 2016. Effect of bacteria isolates in powdery mildew control in flowering dogwoods (Cornus florida L.). Crop Prot. 89:51-57. 
Mmbaga, M.T., L.A. Mackasmiel, and F.A. Mrema. 2018. Flowering dogwood infections with Macrophomina phaseolina. HortScience 53:334-336.

Oteino, N., R.D. Lally, S. Kiwanuka, A. Lloyd, D. Ryan, K.J. Germaine, and D.N. Dowling. 2015. Plant growth promotion induced by phosphate solubilizing endophytic Pseudomonas isolates. Front. Microbiol. 6:745, doi: 10.3389/fmicb.2015.00745.

Pleban, S., F. Inge, and I. Che. 1995. Control of Rhizoctonia solani and Sclerotium rolfsii in the greenhouse using endophytic Bacillus spp. Eur. J. Plant Pathol. 101:665-672.

Rowan, S.J. 1971. Soil fertilization, fumigation, and temperature affect severity of black root rot of slash pine. Phytopathology 61:184-187.

Seymour, C.P. 1969a. Charcoal root rot of nurserygrown pines in Florida. Phytopathology 59: 89-92.
Seymour, C.P. 1969b. Charcoal root disease, p. 1113. In: G.W. Peterson and R.S. Smith, Jr. (Tech. Coordinators). Forest Nursery Diseases in the United States. USDA Forest Service. Agr. Hdbk. 470.

Smith, R.S. and R.V. Bega. 1964. Macrophomina phaseoli in the forest tree nurseries of California. Plant Dis. Rep. 48:206.

Smith, G.S. and O.N. Carvil. 1977. Field screening of commercial and experimental soybean cultivars for their reaction to Macrophomina phaseolina. Plant Dis. 81:363-368.

Su, G., S.O. Suh, R.W. Schneider, and J.S. Rissin. 2000. Host specialization in the charcoal rot fungus, Macrophomina phaseolina. Phytopathology $91: 120-126$.

Sturz, A.V., B.R. Christie, and J. Nowak. 2000. Bacterial endophytes: Potential role in developing sustainable systems of crop production. Crit. Rev. Plant Sci. 19:1-30.
Waller, F., B. Achatz, H. Baltruschat, J. Fodor, K. Becker, M. Fischer, T. Heier, R. Hückelhoven, C. Neumann, D. von Wettstein, P. Franken, and K.H. Kogel. 2005. The endophytic fungus Piriformospora indica reprograms barley to saltstress tolerance, disease resistance, and higher yield. Proc. Natl. Acad. Sci. USA 102(38): 13386-13391.

Windham, A.S. 1994. Disease management of woody ornamentals in nurseries and commercial landscapes. University of Tennessee Agricultural Extension Service PB 1234-25M.

Wrather, J.A. 1995. Soybean disease loss estimates for the southern United States, 1974 to 1994. Plant Dis. 79:1076-1079.

Wyllie, T.D. 1988. Charcoal rot of soybean Current status, p. 106-113. In: I.D. Wyllie and K.H. Scott (eds.). Soybean diseases of the North Central Region. The American Phytopathological Society, St. Paul, MN. 